\title{
COMPOSIÇÃO QUÍMICA E DIGESTIBILIDADE EM OVINOS DA GRAMA ESTRELA ENSILADA COM DIFERENTESADITIVOS
}

\author{
Chemical composition and digestibility in sheep of stargrass ensiled with different additives
}

\author{
Valter Harry Bumbieris Junior¹, Clóves Cabreira Jobim² ${ }^{2}$ Moysés Calixto Junior ${ }^{3}$, Ulysses Cecato ${ }^{4}$
}

\begin{abstract}
RESUMO
Objetivou-se com o estudo avaliar a composição química e a digestibilidade aparente em ovinos da grama estrela ensilada com diferentes aditivos. Os aditivos empregados foram o enzimo-bacteriano (em duas concentrações) e a uréia (10 kg/tonelada), totalizando quatro tratamentos. Para o experimento de digestibilidade, foram utilizados quatro ovinos machos castrados distribuídos em delineamento quadrado latino (4x4). Em relação à composição química, as variáveis MS, PB, EE, FDA e LIG apresentaram diferença $(\mathrm{P}<0,05)$ entre os valores obtidos, porém a FDN não mostrou diferença entre tratamentos. Quanto à capacidade tampão e ao pH os menores valores foram obtidos com os tratamentos com aplicação de inoculante. Não houve efeito de tratamento (inoculante ou aplicação de uréia) sobre a digestibilidade da MS, PB e FDN.
\end{abstract}

Termos para indexação: Capim, enzimas, inoculante, ovinos, uréia

\section{ABSTRACT}

The purpose of this study was to evaluate the chemical composition and apparent digestiblity in sheep of stargrass ensilaged with different additives. The additives used were enzyme-bacterial inoculent (in two concentrations) and urea (10 kg/ton), totalling 4 treatments. For the digestability experiment, four male sheep were distributed in a $(4 \mathrm{x} 4)$ latin square design. With respect to chemical composition, the variables; dry matter, crude protein, ether extract, acid detergent fiber, and lignin showed statistical difference $(\mathrm{P}<0,05)$ among the obtained values. However, neutral detergent fiber showed no difference among treatments. Concerning buffering capacity and $\mathrm{pH}$, the lowest values were for silages treated with inoculents. No treatment effects (inoculent or urea application) for dry matter, crude protein, or neutral detergent fiber digestibility of stargrass silages were detected.

Index terms: Enzymes, grass, inoculant, sheep, urea.

(Recebido em 22 de abril de 2008 e aprovado em 25 de novembro de 2008)

\section{INTRODUÇÃo}

O consumo e digestibilidade aparente dos nutrientes são importantes parâmetros que contribuem nas pesquisas de nutrição de ruminantes e desenvolvimento de sistemas de alimentação com o objetivo de descrever o valor nutritivo dos alimentos (Soest, 1994).

Fenos e silagens de gramíneas são alimentos básicos e utilizados com frequência como principal componente da dieta de ruminantes em muitos países do mundo. No Brasil, a utilização de silagem de capim tem aumentado consideravelmente nos últimos anos, em virtude dos resultados de pesquisas sobre ensilagem de gramíneas tropicais e pela maior acessibilidade de maquinário adequado ao corte.

Outro fator que também tem colaborado para o desenvolvimento da pesquisa com silagem de gramíneas tropicais é o desenvolvimento de aditivos enzimáticos e bacterianos. A utilização desses aditivos visa a melhorar a qualidade de fermentação das silagens, principalmente no tocante a alterações na composição da parede celular pelas enzimas e aumento na produção de ácido lático pelas bactérias especializadas.

Ainda como aditivo têm-se utilizado também a uréia, com o objetivo maior de elevar a quantidade de nitrogênio não protéico no material ensilado, além de conservar forragens com alto teor de umidade (Rosa \& Fadel, 2001).

Gramíneas do gênero Cynodon são potencialmente recomendáveis em sistema de produção animal, em razão da capacidade de produção de forragem de boa qualidade e a possibilidade tanto de uso sob pastejo, ou ainda como volumoso conservado (Vilela \& Alvim, 1998). Dentre estas destaca-se a grama estrela (Cynodon nlemfuensis

\footnotetext{
${ }^{1}$ Zootecnista Dr. - Professor do Departamento de Zootecnia/DZO - Universidade Estadual de Maringá/UEM - Av. Colombo, 5790, 87020-900, Maringá/ PR - dudabumbieris@hotmail.com

${ }^{2}$ Zootecnista Dr. - Professor do Departamento de Zootecnia/DZO - Universidade Estadual de Maringá/UEM Av. Colombo, 5790, 87020-900,Maringá/ PR - Pequisador CNPq. - ccjobim@uem.br

${ }^{3}$ Zootecnista, Doutorando em Forragicultura - Departamento de Zootecnia/DZO - Universidade Estadual de Maringá/UEM - Av. Colombo, 5790, 87020900, Maringá/PR -bolsita CNPq - m.cjunior@bol.com.br

${ }_{4}$ Zootecnista Dr. - Professor Titular do Departamento de Zootecnia/DZO - Universidade Estadual de Maringá/UEM Av. Colombo, 5790, 87020900,Maringá/PR - Pequisador CNPq. - ucecato@uem.br
} 
Vanderyst.) pela rápida cobertura do solo, rusticidade e resistência às condições climáticas adversas. Essa gramínea tem sido uma opção interessante não só por essas características, mas também pela elevada produção de forragem.

Todos esses méritos que caracterizam bem essa cultivar faz com que aumente o estimulo à pesquisa dessa espécie para utilização na forma de silagem, principalmente porque a produção de feno tem alguns entraves de ordem climática e econômica em algumas regiões do país.

Portanto, em virtude da escassez de resultados de pesquisa sobre a ensilagem de gramíneas do gênero Cynodon, objetivou-se, com o presente estudo avaliar a composição química e a digestibilidade aparente em ovinos da grama estrela, ensilada com diferentes aditivos.

\section{MATERIAL E MÉTODOS}

O experimento foi realizado no setor de Nutrição de Ruminantes da Fazenda Experimental de Iguatemi e no Laboratório de Análise de Alimentos e Nutrição Animal do Departamento de Zootecnia da Universidade Estadual de Maringá.

Os tratamentos testados foram: $\mathrm{SGE}=$ Silagem de grama estrela (sem uso de aditivo); SGE $150=$ Silagem de grama estrela com uso de aditivo enzimo-bacteriano comercial Katec ${ }^{\circledR}$ Bacto Silo C. Tropical (150g/tonelada de matéria natural); SGE $300=$ Silagem de grama estrela com uso de aditivo enzimo-bacteriano comercial Katec ${ }^{\circledR}$ Bacto Silo C. Tropical (300g/tonelada de matéria natural); SGEU = Silagem de grama estrela com uréia $(10 \mathrm{~kg} /$ tonelada de matéria natural).

As silagens foram confeccionadas em silos experimentais (manilhas de cimento de 1,20 m de diâmetro x 1,0 m de altura) com capacidade para cerca de $1000 \mathrm{~kg}$ de silagem, sendo dois silos por tratamento. A forragem foi colhida com ensiladeira modelo JF90 e, no momento da ensilagem, o inoculante foi aspergido com uma bomba pulverizadora no material a ser ensilado, na quantidade de dois litros de água por silo, enquanto a uréia foi distribuída manualmente de forma homogênea nos silos. Imediatamente após o enchimento, os silos foram vedados adequadamente. Decorridos 120 dias, esses foram abertos para as avaliações da composição química e digestibilidade em ovinos.

Foram feitas amostragens da grama estrela antes da ensilagem e das silagens nos diferentes períodos do experimento. Essas amostras foram homogeneizadas e acondicionadas em sacos plásticos e armazenadas em freezer a $-20^{\circ} \mathrm{C}$ para posteriores análises químicas. Os teores de matéria seca (MS), proteína bruta (PB) e extrato etéreo
(EE) foram obtidos segundo AOAC (1990). A determinação da fibra em detergente neutro (FDN), fibra em detergente ácido (FDA), nitrogênio indigestível em detergente neutro (NIDN) e lignina (LIG) foram obtidos de acordo com Soest et al. (1991).

A análise da capacidade tamponante das silagens foi realizada segundo Playne \& McDonald (1966). A obtenção do suco da silagem para medida do $\mathrm{pH}$ foi realizada com uso de prensa hidráulica (Tecnal®), com capacidade de força de 16 toneladas. $\mathrm{O} \mathrm{pH}$ foi medido com potenciômetro digital.

Foram utilizados, para o experimento de digestibilidade, quatro ovinos machos, castrados, com 10 meses de idade e pesando aproximadamente $30 \mathrm{~kg}$, distribuídos em delineamento quadrado latino $(4 \mathrm{x} 4)$, com quatro períodos de 15 dias, totalizando 60 dias de período experimental.

As exigências nutricionais para manutenção dos animais foram calculadas segundo o Agricultural and Food Research Council-AFRC (1993). Os animais foram mantidos em gaiolas de metabolismo com piso ripado de madeira, com comedouros e bebedouros individuais, onde receberam alimento duas vezes ao dia, pela manhã $(8 \mathrm{~h})$ e à tarde $(16 \mathrm{~h})$ e água à vontade. As dietas continham $30 \%$ de concentrado (milho, soja e suplemento mineral para ovinos) e $70 \%$ de volumoso, sendo este silagem de grama estrela ensilada com diferentes aditivos.

Os períodos experimentais foram de 15 dias cada, sendo 10 dias para adaptação e cinco dias para colheita das amostras. Do $11^{\circ}$ ao $15^{\circ}$ dias de cada período foram realizadas colheita de fezes para determinação da digestibilidade aparente da MS, FDN e PB. Foram feitas amostragens das silagens, concentrado, sobras e fezes. As fezes foram colhidas uma vez ao dia, às $8 \mathrm{~h}$. Feita a homogeneização do material, era retirada uma alíquota diária de $100 \mathrm{~g}$ para a formação de uma amostra composta por animal e período experimental. Essas amostras foram acondicionadas em sacos plásticos e armazenadas em freezer a $-20^{\circ} \mathrm{C}$

Para obtenção das estimativas de excreção fecal, foi utilizado como indicador a FDN indigestível (FDNi), conforme proposto por Cochran et al. (1986). No entanto, a FDNi foi estimada pela incubação ruminal de filtros F57 da Ankom®, com amostras de aproximadamente 0,5 $\mathrm{g}$ de alimento, sobras e fezes. As amostras foram incubadas em duas cabras fistuladas no rúmen por 144 horas, onde os filtros F57 da Ankom ${ }^{\circledR}$ foram envolvidos por um saco poroso para contensão dos mesmos no rúmen, e ligados a um cordão de náilon de $30 \mathrm{~cm}$, preso a tampa da cânula. Todas as amostras, em cada cabra, 
foram incubadas em duplicata. Após a remoção, ao final do tempo de incubação, os filtros foram lavados em água. Em seguida, foram determinados os teores de FDN, considerado como o FDN indigestível (FDNi). P e 1 a concentração da FDNi determinou-se a excreção fecal dos ovinos pela equação: Excreção fecal $(\mathrm{kgMS})=\mathrm{kg}$ FDNi Ingerido/concentração FDNi nas fezes $(\mathrm{kg} / \mathrm{kg})$. A digestibilidade foi calculada pela equação: $\mathrm{DMS}=100$ $100 \times$ ((\%indicador ingerido $) /(\%$ indicador nas fezes $))$.

Os dados foram analisados estatisticamente pela análise de variância, sendo as médias comparadas pelo teste Tukey a 5\%. As análises estatísticas foram realizadas pelo Sistema de Análises Estatísticas e Genéticas - SAEG, desenvolvido pela Universidade Federal de Viçosa (UFV, 1997).

\section{RESULTADOS E DISCUSSÃO}

Os valores médios dos dados de MS, PB, EE, FDN, FDA e LIG são apresentados na Tabela 1. Constatou-se aumento nos teores de MS das silagens SGE 150 e SGEU em relação à forragem fresca e aos tratamentos SGE $300 \mathrm{e}$ SGE. No entanto, os teores observados estão dentro dos valores considerados adequados para ensilagem recomendados por Silveira (1975), que são em torno de 30 a $35 \%$ de MS

O teor de PB foi maior na silagem SGEU, mostrando coerência com o objetivo de se aplicar uréia à silagem, que é de aumento dos níveis de nitrogênio e valor nutritivo do material ensilado, demonstrando que uma fração significativa do NNP é retido no material.

A silagem SGE 150 manteve os teores de PB equivalente à grama fresca antes da ensilagem, evidenciando poucas perdas desse nutriente no processo.
Já as silagens SGE e SGE 300 mantiveram comportamento contrário, apresentado os menores valores de PB entre os tratamentos.

Em relação ao teor de EE, o menor valor foi observado para a silagem SGEU. Segundo Tarkov \& Feist (1969), as ligações do tipo éster entre a hemicelulose e lignina com grupos de carboidratos são rompidas por amoniólise, com consequente formação de amida. Essa quebra de ligações éster influencia diretamente o conteúdo de EE presente na forrageira. Já o aumento no teor de EE das demais silagens em relação à forragem verde, pode ser atribuído ao efeito de diluição no processo de fermentação das silagens.

Os teores de FDN não apresentaram diferença significativa entre tratamentos, mostrando resultados abaixo dos obtidos por Evangelista et al. (2000), em silagem de grama estrela, com valores em torno de $82 \%$. Porém, em relação à grama fresca antes da ensilagem, observa-se aumento no teor da FDN, provavelmente em virtude do consumo de compostos solúveis advindos do próprio processo de fermentação.

No tocante à fração FDA, os maiores valores foram observados para as silagens SGE 300 e SGEU, o que pode ser justificado pelas maiores perdas de conteúdo celular em virtude da ação dos aditivos sobre constituintes da parede celular. Segundo Harbers et al. (1982), a uréia, sendo hidrolisada e produzindo amônia pode resultar em efeito semelhante ao dos álcalis, expandindo a parede celular da planta após um período de armazenamento. O tratamento SGE 300, em relação ao SGE 150, também pode ter favorecido o processo de maiores perdas de conteúdo celular fazendo com que a relação parede celular/conteúdo celular fosse aumentada, elevando dessa forma os teores de FDA.

Tabela 1 - Composição químico-bromatológica (\% MS), da grama estrela antes e após a ensilagem com uso de aditivo enzimo-bacteriano ou uréia

\begin{tabular}{cccccc}
\hline & \multicolumn{4}{c}{ Tratamentos } \\
\cline { 2 - 6 } & GE & SGE & SGE 150 & SGE 300 & SGEU \\
\hline MS (\%) & $29,91 \mathrm{~b}$ & $30,25 \mathrm{~b}$ & $33,85 \mathrm{a}$ & $30,66 \mathrm{~b}$ & $35,97 \mathrm{a}$ \\
PB (\%) & $10,38 \mathrm{~b}$ & $8,92 \mathrm{c}$ & $10,00 \mathrm{~b}$ & $8,34 \mathrm{c}$ & $14,33 \mathrm{a}$ \\
EE (\%) & $1,21 \mathrm{~b}$ & $1,50 \mathrm{a}$ & $1,55 \mathrm{a}$ & $1,58 \mathrm{a}$ & $0,83 \mathrm{c}$ \\
FDN (\%) & $77,44 \mathrm{a}$ & $79,53 \mathrm{a}$ & $78,85 \mathrm{a}$ & $80,12 \mathrm{a}$ & $79,47 \mathrm{a}$ \\
FDA (\%) & $42,88 \mathrm{~b}$ & $43,88 \mathrm{~b}$ & $43,89 \mathrm{~b}$ & $46,72 \mathrm{a}$ & $46,92 \mathrm{a}$ \\
LIG (\%) & $6,16 \mathrm{c}$ & $8,24 \mathrm{~b}$ & $8,04 \mathrm{~b}$ & $7,81 \mathrm{~b}$ & $8,79 \mathrm{a}$ \\
\hline
\end{tabular}

GE = grama estrela; $\mathrm{SGE}=$ Silagem de grama estrela sem uso de aditivo SGE $150=$ Silagem de grama estrela com aditivo Katec ${ }^{\circledR}$ Katec ${ }^{\circledR}$ Bacto Silo C. Tropical $\left(150 \mathrm{~g}\right.$ aditivo/ton de matéria natural); SGE $300=$ Silagem de grama estrela com aditivo Katec ${ }^{\circledR}$ Bacto Silo C. Tropical (300g aditivo/ton de matéria natural); SGEU = Silagem de grama estrela com uréia (10 kg/tonelada matéria natural).

Médias seguidas por letras diferentes na mesma linha, diferem $(\mathrm{P}<0,05)$ pelo teste Tukey a 5\% de probabilidade. 
Da mesma forma, o efeito de concentração dos componentes da parede celular também foi evidenciado quando se comparou com relação à grama fresca, mostrando que provavelmente ocorreram perdas de conteúdo celular no processo de fermentação.

Quanto aos teores de lignina, o valor mais alto foi observado na silagem SGEU. A maior diferença entre as silagens chegou a 12,5\%. Quando comparados os valores com os da grama fresca, observamos o mesmo comportamento de concentração de parede celular nas silagens, demonstrando mais uma vez que o próprio efeito da fermentação faz com que ocorra o consumo de compostos solúveis e geração de ácidos orgânicos. Esses não são mensurados nas análises de fibra ou carboidratos, aumentando, portanto, a concentração de componentes da parede celular.

Os valores médios da capacidade tampão e de $\mathrm{pH}$ das silagens de grama estrela são mostrados na Figura 1. As silagens com aplicação de inoculantes enzimobacterianos apresentaram os menores valores de capacidade tampão, seguido da silagem isenta de aplicação de aditivo. A silagem SGEU (74,4 m.eq NaOH/100 g MS) foi a que apresentou os maiores valores para essa variável.

$\mathrm{O}$ aumento da capacidade tamponante da silagem SGEU provavelmente é advindo do meio alcalino gerado pela uréia, reagindo com o material ensilado, dando maior resistência à diminuição do $\mathrm{pH}$. McDonald et al. (1991), relataram que os produtos de desdobramento das proteínas promovem grande aumento da capacidade tamponante. Portanto, é justificável o maior valor de capacidade tampão para o tratamento com aplicação de uréia, visto que, o desdobramento da uréia à amônia disponibiliza grande quantidade de nitrogênio na massa ensilada dificultando a queda do $\mathrm{pH}$ da mesma.

De modo contrário, o menor valor foi observado no tratamento SGE 300 (44,4 m.eq NaOH/100 g MS), pois o provável aumento na concentração de bactérias nestas favoreceu a produção de ácidos. As silagens com aplicação de inoculantes enzimo-bacterianos apresentaram os menores valores de $\mathrm{pH}$, sendo que a silagem SGE 300 apresentou o menor valor, seguido da silagem SGE 150.

Hubber \& Thomas (1971) e Gonçalves (1978), também observaram maiores valores de $\mathrm{pH}$ nas silagens tratadas com uréia, mantendo a teoria de que, o uso de quantidades maiores de uréia pode interferir no $\mathrm{pH}$ das silagens.

Os valores médios de ingestão de matéria seca, digestibilidade aparente da matéria seca (DMS), proteína bruta e fibra em detergente neutro são apresentados na Tabela 2. A variável ingestão de matéria seca (IMS) não apresentou efeito significativo $(\mathrm{P}>0,05)$ entre os tratamentos, não havendo rejeição dos animais quanto às silagens, inclusive no tratamento com aplicação de uréia (SGEU), onde havia odor de amônia.

As silagens com aplicação de inoculante (SGE 150 e SGE 300) e a silagem sem uso de aditivo (SGE) não diferiram entre si $(\mathrm{P}<0,05)$ para as variáveis analisadas, mostrando que a aplicação do inoculante não alterou a digestibilidade da MS, PB e FDN em relação à silagem sem aplicação de aditivo. A silagem com aplicação de uréia (SGEU), também não apresentou diferenças significativas com relação às variáveis DMS e DFDN, porém com relação à variável $\mathrm{DPB}$, esta apresentou os menores valores $(\mathrm{P}>0,05)$.

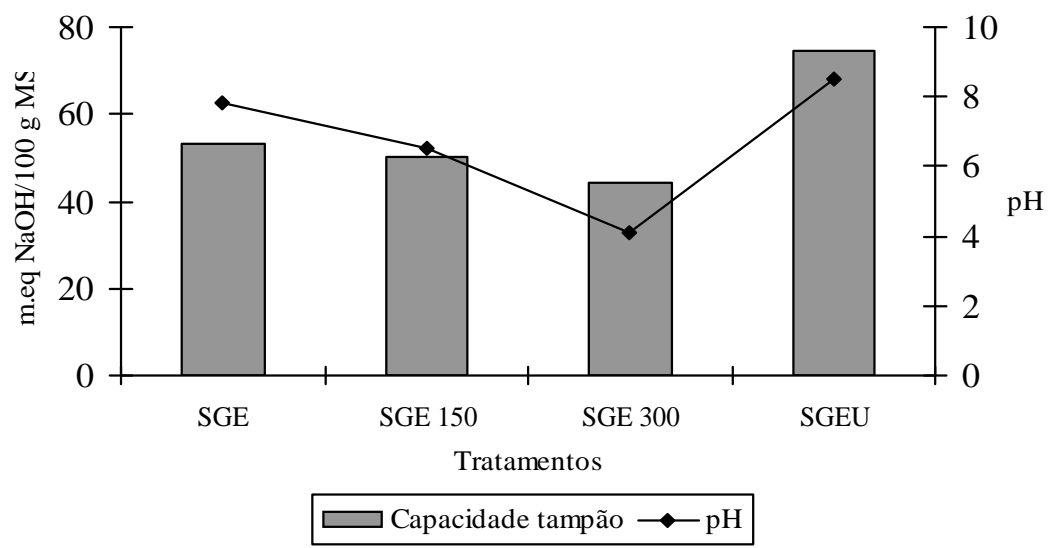

Figura 1 - Capacidade tampão (m.eq NaOH/100 g MS) e pH de silagens de grama estrela com diferentes aditivos, observados no painel dos silos. 
Tabela 2 - Ingestão de Matéria Seca (IMS), Digestibilidade Aparente da Matéria Seca (DMS), Proteína Bruta (DPB) e Fibra em Detergente Neutro (DFDN) da grama estrela ensilada com diferentes aditivos.

\begin{tabular}{|c|c|c|c|c|c|}
\hline & \multicolumn{4}{|c|}{ Tratamentos } & \multirow[b]{2}{*}{$\mathrm{CV} \%$} \\
\hline & SGE & SGE 150 & SGE 300 & SGEU & \\
\hline IMS (kg MS/dia) & $1,10 \mathrm{a}$ & $1,13 \mathrm{a}$ & $1,02 \mathrm{a}$ & $1,10 \mathrm{a}$ & 13,72 \\
\hline DMS (\%) & $71,10 \mathrm{a}$ & $69,50 \mathrm{a}$ & $63,70 \mathrm{a}$ & $58,65 \mathrm{a}$ & 8,45 \\
\hline $\mathrm{DPB}(\%)$ & $73,96 \mathrm{ab}$ & $75,80 \mathrm{a}$ & $63,60 \mathrm{ab}$ & $55,42 \mathrm{~b}$ & 11,62 \\
\hline $\operatorname{DFDN}(\%)$ & $44,52 \mathrm{a}$ & $43,80 \mathrm{a}$ & $36,10 \mathrm{a}$ & $32,51 \mathrm{a}$ & 14,42 \\
\hline
\end{tabular}

SGE = Silagem de grama estrela sem uso de aditivo SGE $150=$ Silagem de grama estrela com aditivo Katec® Katec $($ Bacto Silo C. Tropical (150g aditivo/ton de matéria natural); SGE 300 = Silagem de grama estrela com aditivo Katec® Bacto Silo C. Tropical (300g aditivo/ton de matéria natural); $\mathrm{SGEU}=$ Silagem de grama estrela com uréia $(10 \mathrm{~kg} /$ tonelada matéria natural $) ; \mathrm{CV} \%=$ Coeficiente de variação.

Médias seguidas por letras diferentes na mesma linha, diferem $(\mathrm{P}<0,05)$ pelo teste Tukey a 5\% de probabilidade

Ely et al. (1981), também não encontraram efeitos do uso de inoculante bacteriano sobre a recuperação de nutrientes nas silagens de leguminosas e gramíneas. Esse comportamento também foi observado na digestibilidade das variáveis avaliadas neste estudo. Apesar de ter superado em 1,84 pontos percentuais os valores para a DPB a silagem SGE 150 não foi superior $(\mathrm{P}>0,05)$ a silagem SGE, supondo, portanto, que a dosagem aplicada provavelmente não melhorou a qualidade de conservação da forragem, não alterando de forma significativa também os valores para digestibilidade da MS e da FDN. O mesmo comportamento foi verificado para o tratamento SGE 300, não melhorando a digestibilidade das frações MS, PB e FDN.

Pereira \& Silva (1976), estudando a adição de 0,5 e $0,75 \%$ de uréia ao milho, no ato da ensilagem, observaram em ensaio de digestibilidade, feito com ovinos, apenas melhoria na digestibilidade aparente da proteína bruta. Segundo Gonçalves (1978), a adição de uréia apresenta efeito benéfico no material a ensilar sobre a digestibilidade da matéria seca, porém utilizando materiais de baixa qualidade.

Henrique (1990) também não encontrou resultados positivos na utilização de aditivos enzimo-bacterianos sobre a qualidade de fermentação e digestibilidade de capins tropicais. Coan et al. (2001) avaliando o efeito do inoculante enzimo-bacteriano (Bacto Silo C. () na composição química, digestibilidade e parâmetros qualitativos das silagens de capins Panicum maximum Jacq. colhidos aos 45 e 60 dias, concluíram que o uso do inoculante não melhorou as características estudadas, independentemente do cultivar e da idade de corte.

Porém, alguns outros autores (Haigt \& Chapple, 1998; Yan et al., 1998; Andrade, 2000), obtiveram sucesso no processo fermentação das silagens de gramíneas tropicais e também na digestibilidade da matéria orgânica, FDN e FDA de gramíneas inoculadas com aditivos enzimobacterianos.

Nota-se certa disparidade entre a hipótese e os dados obtidos neste estudo, mostrando que as dificuldades em se preservar gramíneas não são somente quanto ao processo fermentativo, mas também com relação à estabilidade desse material, após a abertura do silo. De acordo com Cai et al. (1999) silagens bem preservadas são frequentemente consideradas mais propensas à deterioração aeróbia que silagens mal fermentadas. A deterioração aeróbia resulta em perdas de MS e de importantes componentes nutricionais pela oxidação de ácido lático e de carboidratos solúveis.

Segundo Jobim et al. (2002), a presença de fungos pode alterar a palatabilidade e também a concentração de nutrientes na silagem, principalmente em relação à concentração de carboidratos solúveis e vitaminas. De acordo com Schlatter \& Smith (1999), a degradação de proteína tem grande impacto econômico, e as alterações na concentração de nutrientes aliada à redução no consumo, afetam negativamente a digestibilidade do alimento.

A coloração da silagem do tratamento com aplicação de uréia era mais escura em relação às demais, o que evidencia a ocorrência da reação química da fração fibrosa e a amônia (Sundstol \& Coxworth, 1984; Schiere \& Nell, 1993). Porém, ao contrário do que se esperava, não houve decréscimo nos teores de FDN, o que também não aconteceu com a digestibilidade da FDN e da MS que mantiveram os menores valores $(\mathrm{P}>0,05)$ em relação aos outros tratamentos, além de apresentar valores inferiores $(\mathrm{P}>0,05)$ da DPB com relação aos demais tratamentos. Provavelmente, no momento da abertura do silo houve volatilização da amônia, com perdas significativas de 
nitrogênio, o que poderia ter influenciado negativamente os resultados de digestibilidade aparente da PB.

\section{CONCLUSÕES}

A uréia elevou a percentagem de proteína bruta da silagem, mas não teve efeito na fração FDN. A adição do aditivo enzimo-bacteriano não melhorou as características químicas da silagem em relação à forragem verde.

O uso de inoculante enzimo-bacteriano reduziu e a uréia aumentou a capacidade tampão das silagens de grama estrela.

A aplicação do inoculante enzimo-bacteriano, assim como a aplicação de uréia, não melhorou a digestibilidade da matéria seca, proteína bruta e fibra em detergente neutro das silagens de grama estrela.

\section{REFERÊNCIAS BIBLIOGRÁFICAS}

AGRICULTURALAND FOOD RESEARCH COUNCIL. Energy and protein requirements of ruminant. Wallingford: CABI International, 1993. 159p.

ANDRADE, S.T.J. Avaliação de inoculantes biológicos nas silagens de milho, sorgo, capim elefante e alfafa. 2000. 114p. Tese (Doutorado em Zootecnia)-Faculdade de Medicina Veteninária e Zootecnia, Botucatu, 2000.

\section{ASSOCIATION OF OFFICIAL ANALYTICAL CHEMISTS. Organization methods of AOAC. 15.ed. Washington, 1990. 1017p.}

CAI, Y.; BENNO, Y.; OGAWA, M.; KUMAI, S. Effect of applying lactic acid bacterial isolated from forage crops on fermentation characteristics and aerobic deterioation of silage. Journal of Dairy Science, Savoy, v.82, p.520526, 1999.

COAN, R.M.; VIEIRA, P.F.; SILVEIRA, R.N.; REIS, R.A.; MALHEIROS, E.B.; PEDREIRA, M.S. Efeito do inoculante enzimático-bacteriano sobre a composição química, digestibilidade e qualidade das silagens dos capins Tanzânia e Mombaça. In: REUNIÃO DA SOCIEDADE BRASILEIRA DE ZOOTECNIA, 38., 2001, Piracicaba. Anais... Piracicaba: SBZ, 2001. p.124-126.

COCHRAN, R.C.; ADAMS, D.C.; WALLACE, J.D.; GALYEAN, M.L. Predicting digestibility of different diets with internal markers: evaluation of four potential markers. Journal of Animal Science, Savoy, v.63, n.5, p.1476-1483, 1986.
ELY, L.O.; SUDWEEKS, E.M.; MOON, N.J. Inoculation with Lactobacillus plantarun to alfafa, corn, sorghum, and wheat silages. Journal of Dairy Science, Savoy, v.64, n.12, p.2378-2387, 1981.

EVANGELISTA, A.R.; LIMA, J.A.; BERNARDES, T.F. Avaliação de algumas características da silagem de gramínea estrela roxa (Cynodon nlemfuensis Vanderyst). Revista Brasileira de Zootecnia, Viçosa, v.29, n.4, p.941946, 2000 .

GONÇALVES, L.C. Digestibilidade aparente da silagem de milho, com uréia mais carbonato de cálcio e rolão de milho. 1978. 81p. Dissertação (Mestrado)-Escola de Veterinária, Universidade Federal de Minas Gerais, Belo Horizonte, 1978.

HAIGH, P.M.; CHAPPLE, D.G. The effect of formic acid with formalinaddition and wilting on silgae fermentation and intake, and on liveweight change of young cattle. Journal of Agricultural Engineering Research, Silsoe, v.69, n.2, p.179-183, 1998.

HARBERS, L.H.; KREITNER, G.L.; DAVIS, J.G.; RASMUSSEM, M.A.; CORAH, L.R. Ruminal hidroxide treated wheat straw observed by seaning eletron microscopy. Journal of Animal Science, Manhattan, v.54, n.6, p.1309-1319, 1982.

HENRIQUE, W. Efeito do uso de aditivos enzimobacterianos sobre a qualidade da silagem de capim elefante (Pennisetum purpureum, SCHUM). 1990. 100p. Dissertação (Mestrado em Agronomia)-Universidade de São Paulo, Piracicaba, 1990.

HUBBER, J.T.; THOMAZ, J.W. Urea treated corn silage in cow protein rations for lactating cows. Journal of Dairy Science, Champaign, v.54, n.2, p.224-230, 1971.

JOBIM, C.C.; BRANCO, A.F.; GAI, V.F. Qualidade de forragens conservadas versus produção e qualidade do leite de vacas. In: SIMPÓSIO SOBRE SUSTENTABILIDADE DA PECUÁRIA LEITEIRA NA REGIÃO SUL DO BRASIL, 2., 1991, Maringá. Anais.. Maringá, 2002. p.98-122.

McDONALD, P.; HENDERSON, A.R.; HERON, S. The biochemistry of silage. 2.ed. Marlow: Chalcombe, 1991. 340p. 
PEREIRA, J.M.; SILVA, J.F.C. da. Efeito da adição de uréia e biureto sobre as características e valor nutritivo da silagem de milho. Revista Brasileira de Zootecnia, Viçosa, v.5, n.2, p.188-209, 1976.

PLAYNE, M.J.; McDONALD, P. The buffering constituints of herbage and silage. Journal of Science Food Agricultural, London, v.17, p.262-268, 1966.

ROSA, B.; FADEL, R. Uso da amônia anidra e de uréia para melhora o valor alimentício de forragens conservadas. In: SIMPÓSIO SOBRE PRODUÇÃO E UTILIZAÇÃO DE FORRAGENS CONSERVADAS, 2001, Maringá. Anais... Maringá, 2001. p.40-63.

SCHIERE, J.B.; NELL, A.J. Feeding of urea treated straw in the tropics: I., a review of its technical principles and economics. Animal Feed Science and Tecnology, Amsterdam, v.43, n.1/2, p.135-147, 1993.

SCHLATTER, L.K.; SMITH, K. Effects of mold grow on nutrient availability in animal feeds. In: STATE APPLIED NUTRITION AND MANAGEMENT CONFERENCE, 4., 1999, Iowa Proceedings... Iowa: University of Wisconsin-Extension, 1999. p.139-144.

SILVEIRA, A.C. Técnicas para produção de silagens. In: SIMPÓSIO SOBRE MANEJO DE PASTAGENS, 2., 1975, Piracicaba. Anais... Piracicaba: ESALQ, 1975. p.156-180.

SOEST, P.J. van. Nutritional ecology of the ruminant. 2.ed. Ithaca: Cornell University, 1994. 476p.
SOEST, P.J. van; ROBERTSON, J.B.; LEWIS, B.A. Methods for dietary fiber, neutral detergent fiber, and nonstarch polysaccharides in relation to animal nutrition. Journal of Dairy Science, Champaign, v.74, n.12, p.3583-3597, 1991.

SUNDSTOL, F.; COXWORTH, E.M. Ammonia treatment. In: SUNDSTOL, F.; OWEN, E. (Eds.). Straw and others fibrous by-products as feed. Amsterdam: Elsevier, 1984. p.196-247.

TARKOV, H.; FEIST, W.C. A mechanism for improving the digestibility of lignocelulosic material with dilute alkali and liquid ammonia. Advances in Chemistry Series, Washington, v.26, n.1, p.13-21, 1969.

UNIVERSIDADE FEDERAL DE VIÇOSA. Sistema para análises estatísticas e genéticas: manual do usuário. Versão 7.1. Viçosa, MG, 1997. 150p.

VILELA, D.; ALVIM, M.J. Manejo de pastagens do gênero Cynodon: introdução, caracterização e evolução do uso no Brasil. In: SIMPÓSIO SOBRE MANEJO DE PASTAGENS, 15., 1998, Piracicaba. Anais... Piracicaba: ESALQ, 1998. p.23-54.

YAN, T.; PATTERSON, D.C.; GORDON, F.J.; KILPATRICK, D.J. Effects of bacterial inocutation of unwilted and wilted grass silage: 2., intake, performance and eating behaviour by dairy cattle. Journal of Agricultural Science, Cambridge, v.131, n.1, p.103-113, 1998. 